\title{
NIOBIUM-TIN MAGNET TECHNOLOGY DEVELOPMENT AT FERMILAB *
}

\author{
D.R. Chichili ${ }^{+}$, T.T. Arkan, I. Terechkine, Fermilab, Batavia, IL, USA \\ J.A. Rice, Composite Technology Development Inc., Lafayette, CO, USA
}

\section{Abstract}

As a part of the Fermilab high field $\mathrm{Nb}_{3} \mathrm{Sn}$ dipole development program, various issues of magnet technology are being investigated. In cable insulation development, S-2 fiber glass sleeve and a new ceramic insulation developed by Composite Technology Development Inc. (CTD) were studied as a possible candidates. For each type of insulation, $\mathrm{Nb}_{3} \mathrm{Sn}$ ten-stack samples were reacted and then vacuum impregnated with epoxy. Measurements of modulus of elasticity and Poisson's ratio under compression were made at room temperature and at $4.2 \mathrm{~K}$. For comparison, an epoxy impregnated NbTi composite was also tested.

\section{INTRODUCTION}

Fermilab, in collaboration with LBNL and KEK, is developing a high field $\mathrm{Nb}_{3} \mathrm{Sn}$ dipole for use in the next generation Hadron Collider. The conceptual design for the first magnet, detailed in [1], is based on a 2-layer $\cos \theta$ coil structure and cold iron yoke. As a part of this program, various issues of the magnet technology such as cable insulation, heat-treatment, epoxy impregnation and thermo-mechanical properties of the composite are being investigated. Due to limited space, this paper presents results only in the azimuthal direction. Readers are referred to [2] for more results.

\section{SAMPLE PREPARATION}

\subsection{Cable Parameters}

A summary of $\mathrm{Nb}_{3} \mathrm{Sn}$ and $\mathrm{NbTi}$ cable parameters used in the present study are given on Table 1 . The variation of $\mathrm{Nb}_{3} \mathrm{Sn}$ cable mid-thickness with pressure before and after reaction is shown in Fig. 1. The cable mid-thickness increases with reaction and decreases with pressure [3]. On the other hand, the cable length contracted by about $4.5 \mu \mathrm{m} / \mathrm{mm}$ and the cable width increased from 14.232 $\mathrm{mm}$ to $14.669 \mathrm{~mm}$ due to reaction. Note that these measurements are taken at zero pressure.

\subsection{Cable Insulation}

The most common insulation material used for $\mathrm{Nb}_{3} \mathrm{Sn}$ cables is S-2 fiber glass either in tape form or sleeve $[4,5]$.
In the present work, we investigated S-2 fiber glass sleeve and a new ceramic insulation.

Table 1: Cable Parameters

\begin{tabular}{||l|c|c||}
\hline & $\mathbf{N b}_{3} \mathbf{S n}$ & $\mathbf{N b T i}$ \\
\hline Number of Strands & 28 & 38 \\
\hline Strand diameter & $1.012 \mathrm{~mm}$ & $0.808 \mathrm{~mm}$ \\
\hline Cable Thickness & $1.7852 \mathrm{~mm}$ & $1.4573 \mathrm{~mm}$ \\
\hline Cable Width & $14.232 \mathrm{~mm}$ & $15.3943 \mathrm{~mm}$ \\
\hline Keystone angle & $0.91 \mathrm{deg}$. & $1.038 \mathrm{deg}$. \\
\hline
\end{tabular}

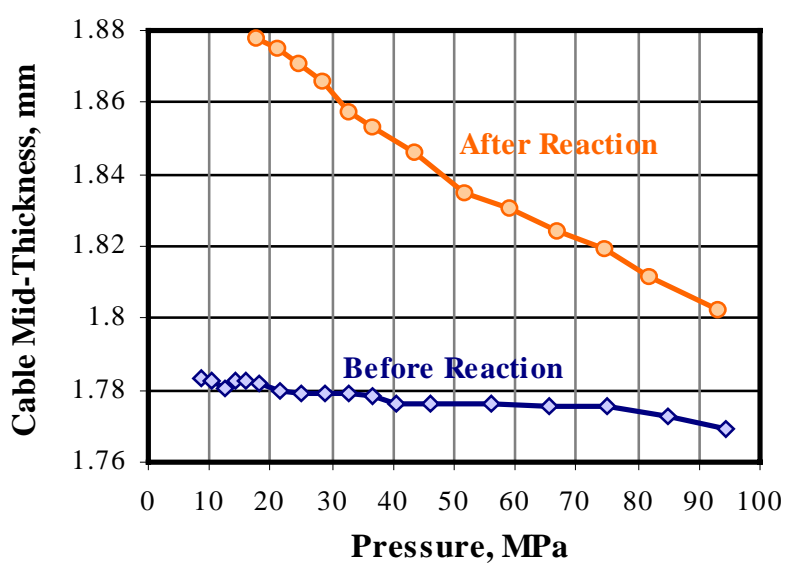

Figure 1: Variation of cable thickness with pressure.

The organic binder used on the S-2 fiber glass sleeve which provides protection/lubrication for the glass strands during processing left a carbon residue during reaction under argon atmosphere. This could create turn to turn shorts in the coil. So the sleeve was first heat-treated at $450{ }^{\circ} \mathrm{C}$ in air to remove the binder and a different binder was applied that would not leave much carbon residue during reaction $[5,6]$.

Ceramic tape on the other hand does not have any organic sizing. The binder (CTD-1002x) which is applied to the tape is also inorganic and can be used to preform the coils in shape before reaction by curing at $120^{\circ} \mathrm{C}$ for $30 \mathrm{~min}$. Hence with the binder we can have a insulated and cured coil before reaction which helps to define the coil shape. This also makes the coils easier to handle. After reaction the ten-stack samples remain bonded together, however the binder became porous and formed crystals due to shrinkage. This is useful as it allows the epoxy to penetrate during impregnation.

\footnotetext{
"Work supported by the U.S. Department of Energy
}

+Email: chichili@fnal.gov 


\subsection{Epoxy Impregnation}

Insulated ten-stack samples were first reacted and then vacuum impregnated with CTD-101K. Note that the samples were compressed with a pusher block during impregnation and the effect of this impregnation pressure on the mechanical behavior was also investigated. Fig. 2 shows an epoxy impregnated composite with direction convention used in this paper.

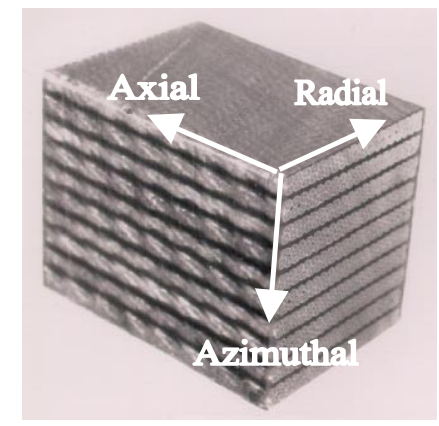

Figure 2: Epoxy impregnated composite.

\section{MECHANICAL PROPERTIES}

Strain gauges were mounted to measure strains both in the direction of load and transverse to the direction of the load. A calibrated load cell was used to record the force applied on the sample. Both monotonic and load-unloadreload tests were performed at $300 \mathrm{~K}$ and at $4.2 \mathrm{~K}$ and the test results are discussed below.

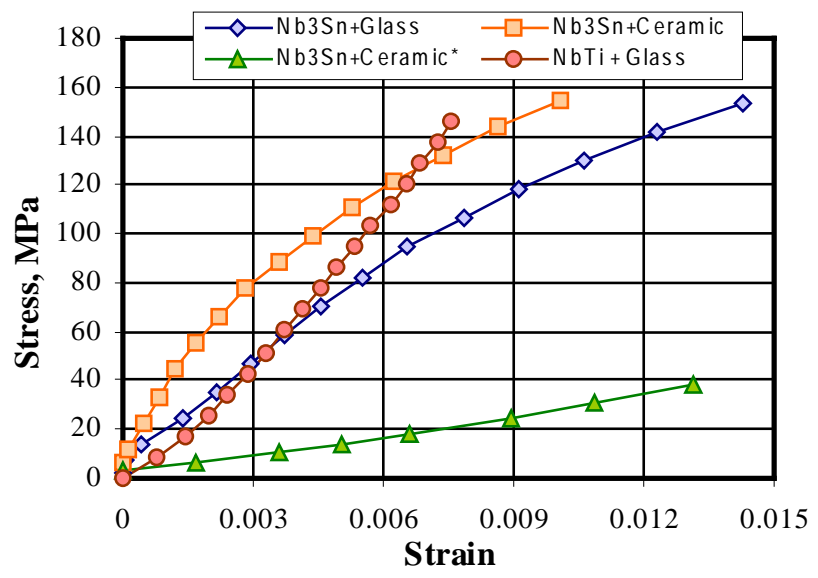

Figure 3: Mechanical behavior at room temperature. $\left(* \mathrm{Nb}_{3} \mathrm{Sn}\right.$ stack with ceramic insulation cured and reacted; but not impregnated ).

\subsection{Azimuthal Direction: Monotonic Loading}

Fig. 3 shows the test results at room temperature. Note that the $\mathrm{Nb}_{3} \mathrm{Sn}$ composite exhibits non-linear behavior in contrast to the linear behavior observed for $\mathrm{NbTi}$ composite. This behavior of $\mathrm{Nb}_{3} \mathrm{Sn}$ composite was first thought to be due to low impregnation pressure (10 $\mathrm{MPa}$ ) compared to NbTi composite (45 $\mathrm{MPa})$. To test this hypothesis, another $\mathrm{Nb}_{3} \mathrm{Sn}$ composite was fabricated at higher impregnation pressure (45 $\mathrm{MPa}$ ) and tested. The results shown in Fig. 4 show that the mechanical response in azimuthal direction does not depend on impregnation pressure.

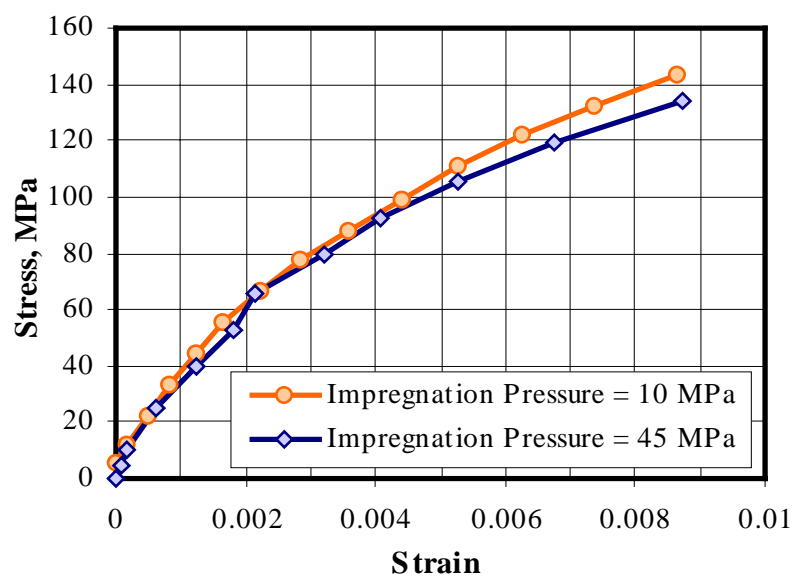

Figure 4: Effect of impregnation pressure.

The effect of temperature on the mechanical response of $\mathrm{Nb}_{3} \mathrm{Sn}$ composite is shown in Fig. 5. There is significant increase in the modulus for $\mathrm{Nb}_{3} \mathrm{Sn}$ composite with $\mathrm{S}-2$ glass. However with ceramic insulation, the modulus did not change with temperature except that the composite behavior is more linear at $4.2 \mathrm{~K}$ than at $300 \mathrm{~K}$. This behavior was very repeatable and even the load-unloadreload tests (see next section) show this behavior.

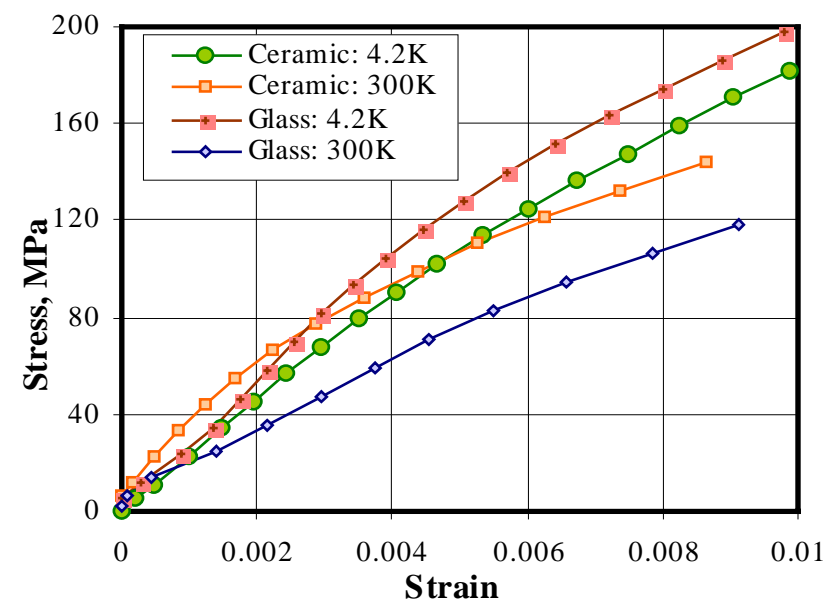

Figure 5: Effect of temperature.

\subsection{Azimuthal Direction: Load-Unload-Reload}

The coils in a magnet are subjected to loading, unloading and reloading repeatedly during assembly, cool-down and excitation. Hence it is very important to understand the mechanical behavior of the composite under these loading conditions. Fig. 6 shows load-unload-reload test results for $\mathrm{Nb}_{3} \mathrm{Sn}$ composite with ceramic insulation both at $300 \mathrm{~K}$ and at $4.2 \mathrm{~K}$. The following observations can be inferred from these results (i) the overall behavior of the composite under loading is similar to that under 
monotonic loading, (ii) there is no apparent change in modulus by decreasing temperature. Fig. 7 shows the behavior of the $\mathrm{Nb}_{3} \mathrm{Sn}$ composite under cyclic loading after initial "massaging" to $100 \mathrm{MPa}$. The results show that we could massage the coils up to a peak stress before assembly, which would then result in a composite with higher modulus and a linear mechanical behavior. This massaging also results in a plastic deformation of $0.3 \%$ in the composite which should be taken into account while designing the magnet cros-section.

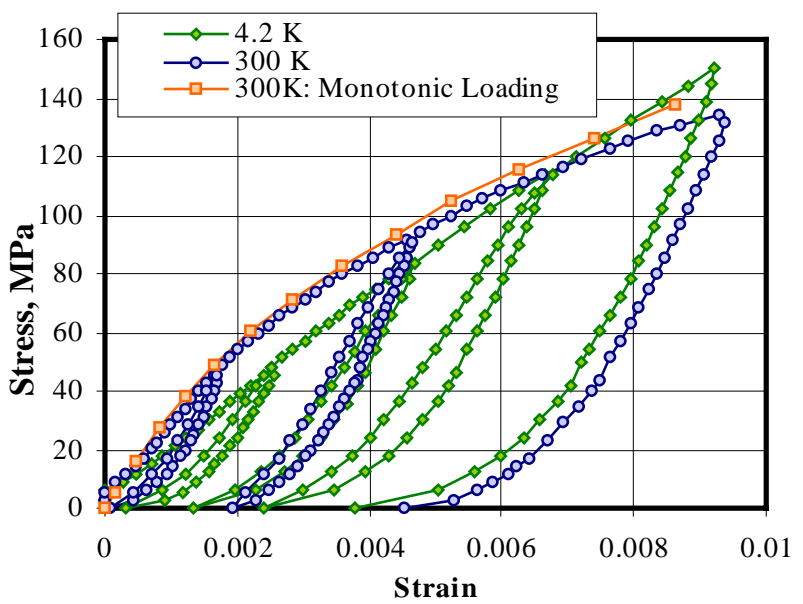

Figure 6: Load-Unload-Reload Tests.

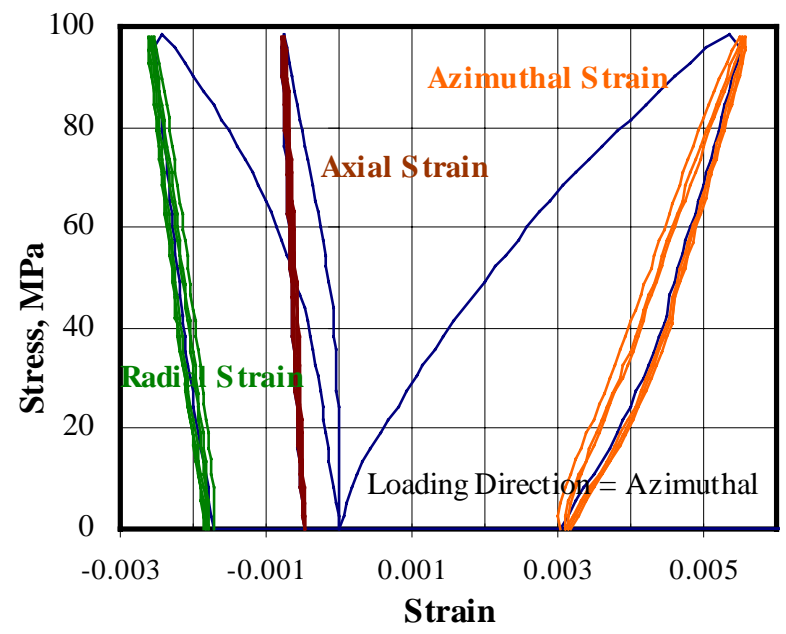

Figure 7: Cyclic loading tests up to a certain stress.

Fig. 7 also shows the Poisson's ratio measurements for the load-unload-reload tests. Note that the Poisson's ratio in the axial direction is higher than in radial direction. Also it remained constant in the axial direction from the first cycle to the second cycle at 0.14 , however in the radial direction it decreased from 0.45 to 0.33 .

Similar load-unload-reload experiments were conducted for the $\mathrm{Nb}_{3} \mathrm{Sn}$ composite with S-2 glass insulation. The mechanical behavior was found to be similar to that with ceramic insulation.

\section{SUMMARY}

Table 2 summarizes the mechanical properties under monotonic loading for different composites tested. At room temperature, the behavior is nonlinear and hence two moduli are specified, one at low pressures and the other at higher pressures. Included in the table also are the data reported by LBNL[5,7] and University of Twente [4]. The moduli of the composite tested here are much lower than that reported by LBNL and higher than that measured at [4]. These differences in the data quoted here and else where in the literature are not understood yet.

Table 3 provides the data for $\mathrm{Nb}_{3} \mathrm{Sn}$ composite after massaging to $100 \mathrm{MPa}$. The idea for the first short model dipole to be built at Fermilab, is to massage the coils to about 100MPa before assembly which would then increase the modulus to $38 \mathrm{GPa}$ both at $300 \mathrm{~K}$ and at $4.2 \mathrm{~K}$ with linear mechanical behavior.

Table 2: Data under monotonic loading.

\begin{tabular}{||c|c|c|c||}
\hline \multirow{2}{*}{ Composite } & \multicolumn{2}{|c|}{ E, GPa } & Poisson's \\
& Ratio \\
\hline $\mathrm{Nb}_{3} \mathrm{Sn}+\mathrm{S}-2$ & 17.5 & 26.0 & $\mathrm{v}_{21}=0.16$ \\
& 6.5 & 14.0 & $\mathrm{v}_{23}=0.46$ \\
\hline $\mathrm{Nb}_{3} \mathrm{Sn}+$ ceramic & 27.0 & 22.0 & $\mathrm{v}_{21}=0.14$ \\
& 10.0 & 14.0 & $\mathrm{v}_{23}=0.45$ \\
\hline $\mathrm{NbTi}+\mathrm{S}-2$ & 20.0 & 32.0 & $\mathrm{v}_{23}=0.29$ \\
\hline $\mathrm{Nb}_{3} \mathrm{Sn}+\mathrm{S}-2[5]$ & 35.0 & & \\
\hline $\mathrm{Nb}_{3} \mathrm{Sn}+\mathrm{S}-2[7]$ & 44.0 & & \\
\hline $\mathrm{Nb}_{3} \mathrm{Sn}+\mathrm{S}-2[4]$ & 2 to 5 & & \\
\hline
\end{tabular}

Table 3: Mechanical properties of the $\mathrm{Nb}_{3} \mathrm{Sn}$ composite after massaging to $100 \mathrm{MPa}$.

\begin{tabular}{||l|c|c|l||}
\hline \multirow{2}{*}{ Composite } & \multicolumn{2}{|c|}{ E, GPa } & \multirow{2}{*}{ Poisson's Ratio } \\
\cline { 2 - 3 } & $\mathbf{3 0 0} \mathbf{K}$ & $\mathbf{4 . 2 K}$ & \\
\hline $\mathrm{Nb}_{3} \mathrm{Sn}+\mathrm{S}-2$ & 39.0 & 40.0 & $\mathrm{v}_{21}=0.15 ; \mathrm{v}_{23}=0.34$ \\
\hline $\mathrm{Nb}_{3} \mathrm{Sn}+$ ceramic & 38.0 & 38.0 & $\mathrm{v}_{21}=0.14 ; \mathrm{v}_{23}=0.33$ \\
\hline
\end{tabular}

\section{REFERENCES}

[1] T. Arkan et al., "Conceptual Design of the Fermilab $\mathrm{Nb}_{3} \mathrm{Sn}$ High Field Dipole Model", PAC, NY (1999).

[2] D.Chichili et al., "Measurements of Thermo-Mechanical Properties of $\mathrm{Nb}_{3} \mathrm{Sn}$ Composite", Fermilab pre-print, FERMILAB-Conf-99/ 052 (1999).

[3] I. Bogdanov et al., "Study of the $\mathrm{Nb}_{3} \mathrm{Sn}$ Cable Characteristics for SC - Quadrupole with High Gradient", MT-15, Beijing, (1997).

[4] A. den Ouden et al., "An Experimental 11.5 T Nb 3 Sn LHC Type of Dipole Magnet", IEEE Transactions of Magnetics, Vol. 30 (1994).

[5] D.Del'Orco et al., "Fabrication and Component Testing Results for a $\mathrm{Nb}_{3} \mathrm{Sn}$ Dipole Magnet", IEEE Trans. of Applied Superconductivity, Vol. 5 (1995).

[6] T.Arkan, et al., "Studies on S-2 Fiber Glass Insulation", Fermilab Technical Note, TD-98-063 (1998).

[7] K.Chow et. al., "Measurements of Modulus of Elasticity and Thermal Contraction of Epoxy Impregnated Niobium-Tin and $\mathrm{Nb}$ Ti Composites", presented at ASC, Palm Desert CA (1998). 